Marzena BANACH-ZIAJA

\section{The furnishing of the urban public spaces in Poland Selected issues}

\section{Introduction}

There can be a few basic kinds of space distinguished: intimate (private) social and public. There might be also spaces, which are created within intermingling of mentioned types, such as: half intimate space (Wejchert, 1993). All of these kinds can be noticed in urban space. They all have certain administration authorities, which decide about their developing and usage, that is about their furnishings. In the case of private space, such as interior courtyards or gardens, their planning and furnishings' selection, not always is appropriate, however they are the results of autonomic decisions made by owners. These elements often become an expression of their individuality (for example: half-private space - front garden). As far as the public spaces are concerned, such as streets, avenues, car parks, squares, parks, playgrounds etc. (in a smaller range social), their final looks is decided by a variety of services. Perhaps, their quantity is the cause of a visible lack of coordination of undertaken acts and initiatives, which in result give incoherent and disorderly image of many cities in Poland. An intensive development of urban spaces and related characteristic economical growth, has been mirrored in spatial development as well. There are lots of new, interesting and well-groomed cities' interiors in Poland, coming to being.

\section{Site-details and their function}

This care for aesthetic side of public space includes the smallest elements of its equipment as well, which appear at the market in huge quantity and variety. They have significant influence on its final shaping, and each tiny change provides sometimes complete makeover of an everyday space's image (for example: change of a bus shelter or change of square's pavement) is noticeable by the users. However, to make them more conspicuous, they have to be much more attractive. The use of interesting form or function guarantees being distinguished from the surroundings, which makes them exceptionally readable (Wejchert, 1984). An appropriate usage of these kinds of elements, along within conscious creating of space, provide a good reception of a single element, shapes and plot of the whole surrounding. These problems apply to bigger and smaller towns and villages as well, that is why they have recently been considered in some law regulations in Poland (Michalak et al., 2003).

The base of this spatial shaping policy is spatial order and sustainable development. According to which, the order is such shaping of space, which creates a harmonized entirety and takes into consideration in orderly relation any conditions and functional, social-economical, environmental, cultural and compositional-aesthetic demands. In spatial planning the environmental protection, health protection or economical

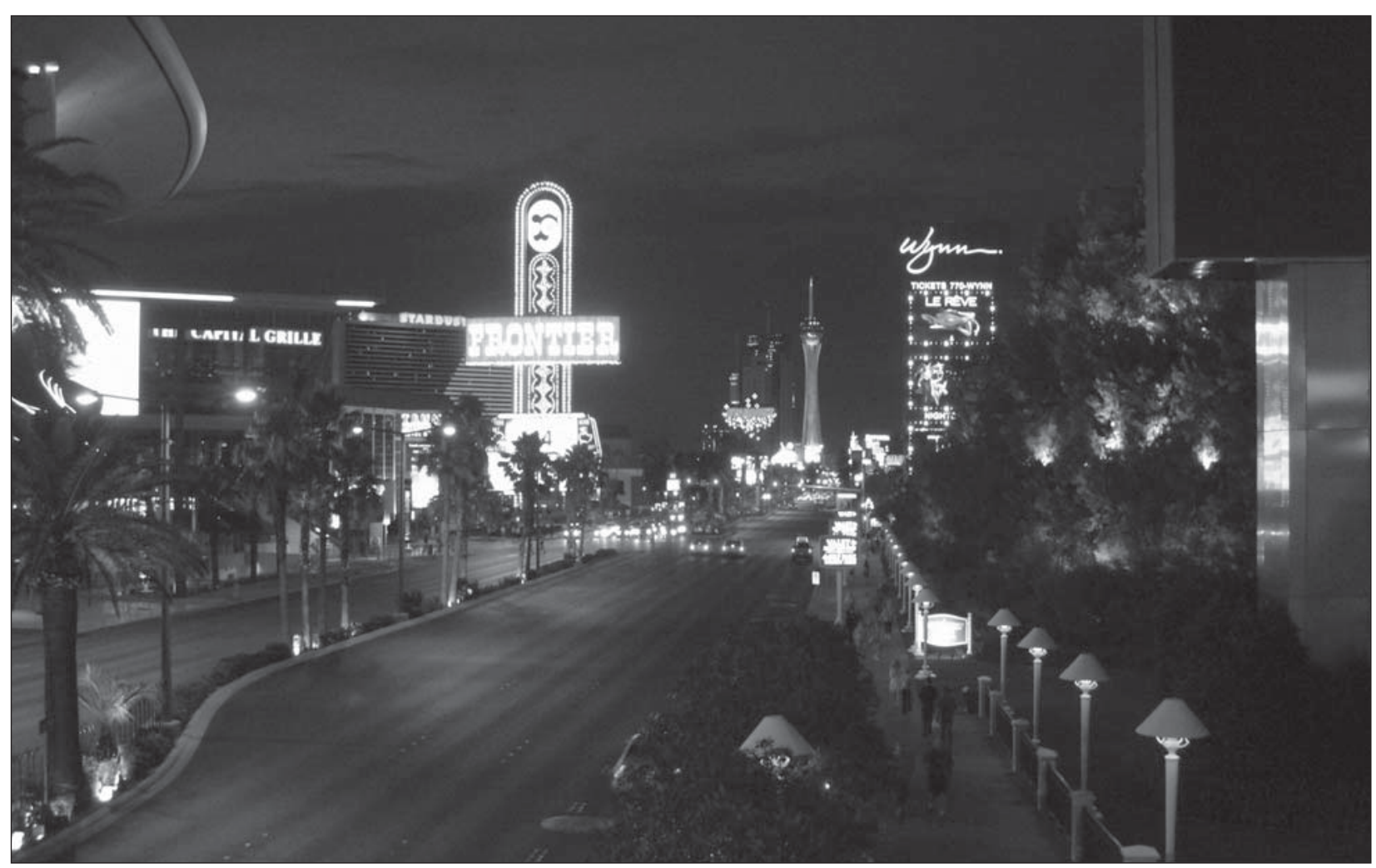

Figure 1: Street-lamps in Las Vegas, USA (source: private archive). 
values are also taken into account, connected with spatial order - including urban planning and architecture and architectural and landscape qualities (Spatial Planning and Developing Law of Poland, 2003). The urban details are the smallest elements, which organize and co-create the city's public space. For cities' users it is not only extensive landscape interior that is important (Figure 1) such as city square, but also a bit smaller details like the street and the furnishing element at the end an architectural and site-detail.

The smaller the town is, the easier and more intensive is reception and recording of those tiny forms. When we arrive at the city or neighbourhood for the first time, we try to find any recognizable spots, which might be helpful in future orientation in that area. Such objects are kind of "distinguishing marks", which are the equivalent of the characteristic features like an original fountain (Figure 2) (Maass et al., 1979). Due to their function, these elements ought to be chosen appropriately to the spot's character and style of the rest of elements in the space. Then, they all are excellently composed with the landscape (Figure 2), becoming objects, which make an orientation in the area quicker and easier.

The telephone booth or street lamp, despite the fact they all are the basic furnishings of any urban space, they sometimes also become almost an accent - symbol, facilitating the identification (for instance - London telephone booth, Figure 3).
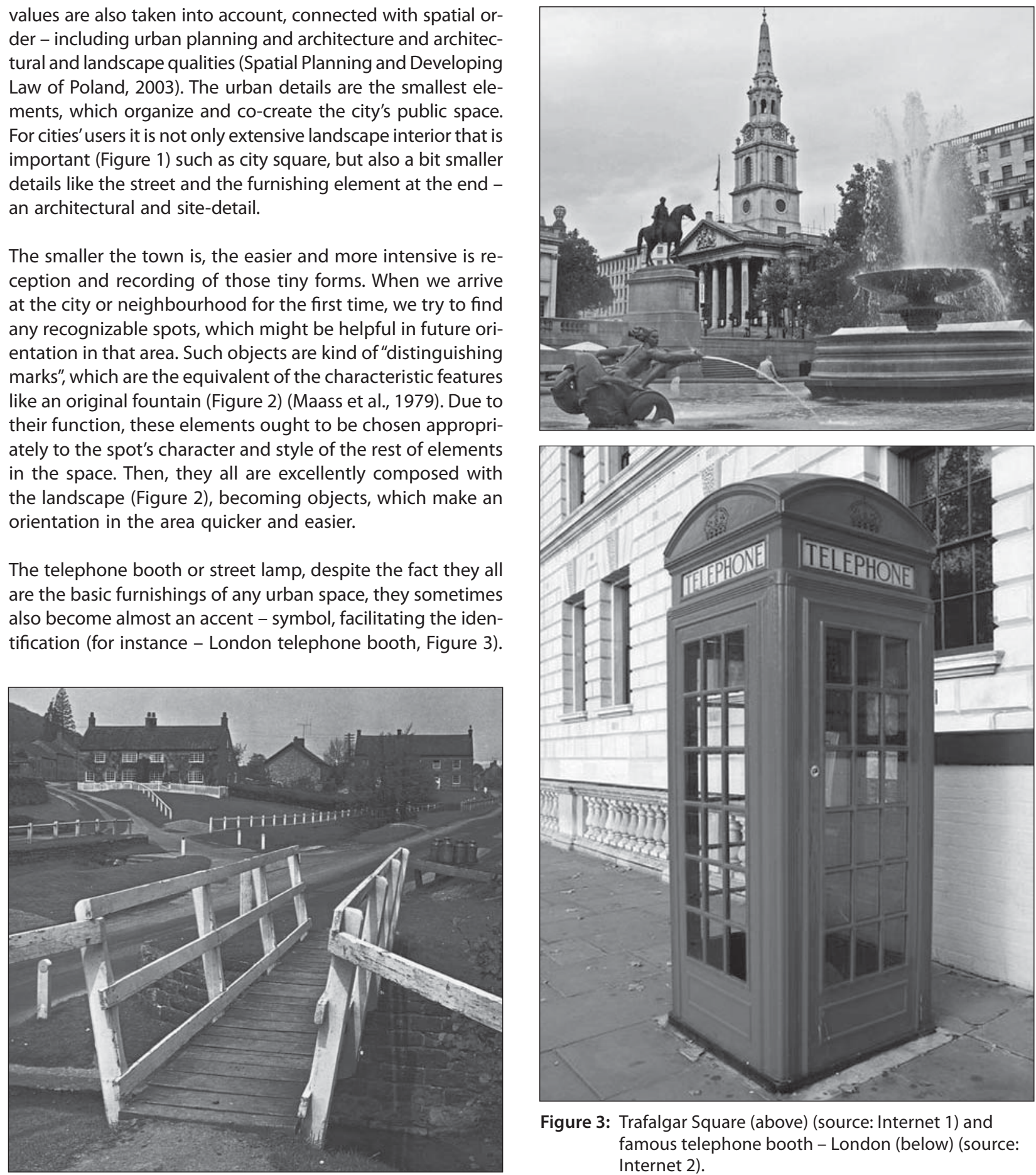

Figure 3: Trafalgar Square (above) (source: Internet 1) and famous telephone booth - London (below) (source: Internet 2).

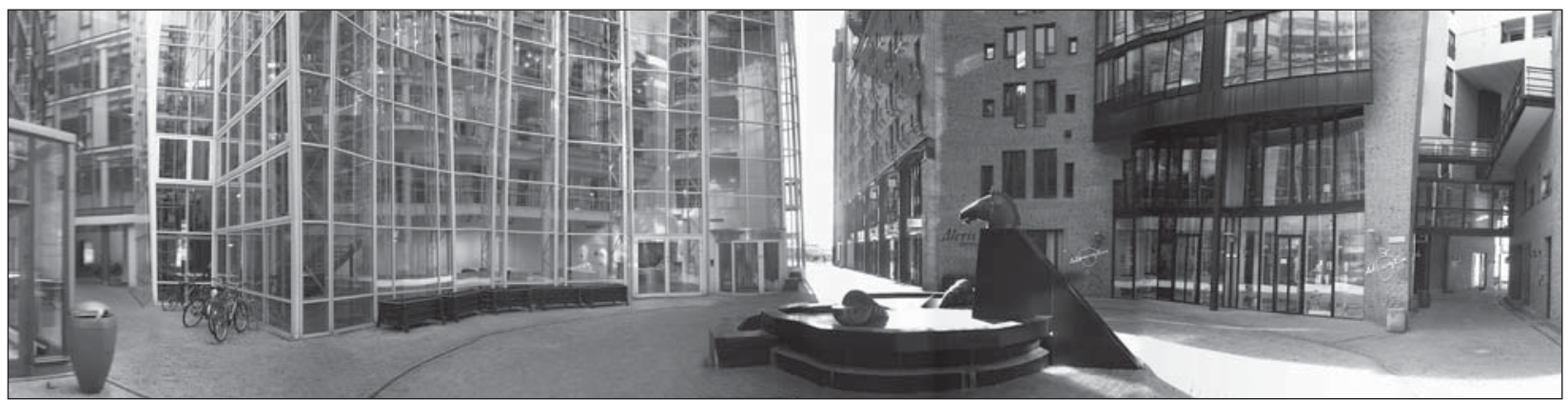

Figure 2: North Yorkshire (above) (source: Picture Book of Britain, 1971: 98 - author: Kenneth Scowen) and Fountain in Oslo (below) (source: Michalak et al., 2003). 


\section{Designing of the furnishing for public spaces}

In big agglomerations, in turn due to the huge variety of forms, functions and scales it seems that it is especially significant to operate skilfully with urban details. The form's clarity and an appropriate colour, to contrast with the background

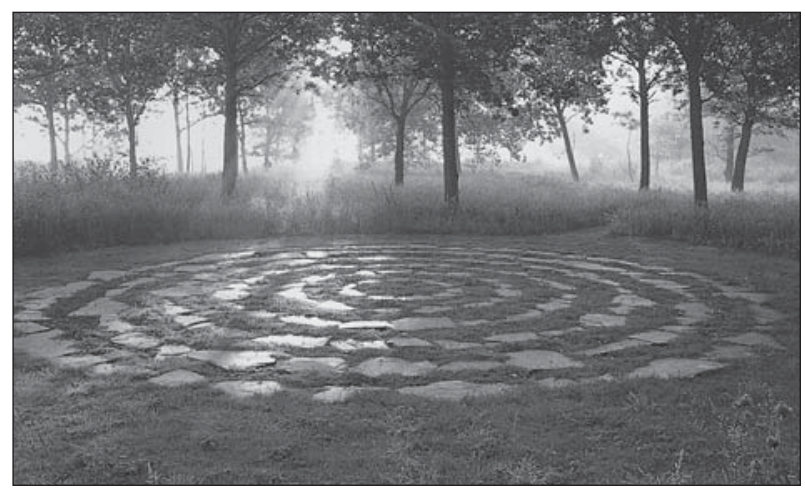

(below) or to harmonize with it (above), ought to be one of their futures.

However, during the process of creation and selection for a certain space (extended study on details by Michalak, 2000) a special attention should be paid to a group of features distinguishing the surrounding. The ideas for new objects with new forms, scale and "language", ought to take into consideration also those already applied, avoiding forms entirely alien to the local planning. The most accurate seems to be a creative designing, innovative, but respectful to the tradition and earlier creation.

"... For a man, the indispensable spatial environment is not only well organized, properly functioning, but also delivering him some aesthetic experiences, including different moods, poetry, symbolism [...] allowing for a relationship of each individual with the city, its' neighbourhood or region" (Wejchert, 1984: 93). A skilful public space furnishing is assured by creating a harmonized composition, which gives a clear

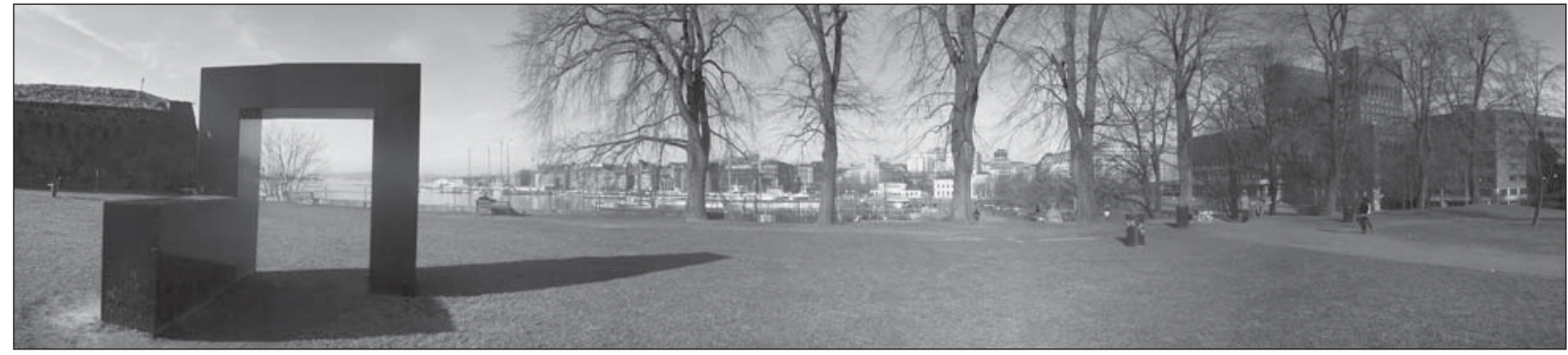

Figure 4: Waterfront Park - USA (above) (source: Cerver, 1996) and Park in Oslo, Norway (below) (source: Michalak et al., 2003).
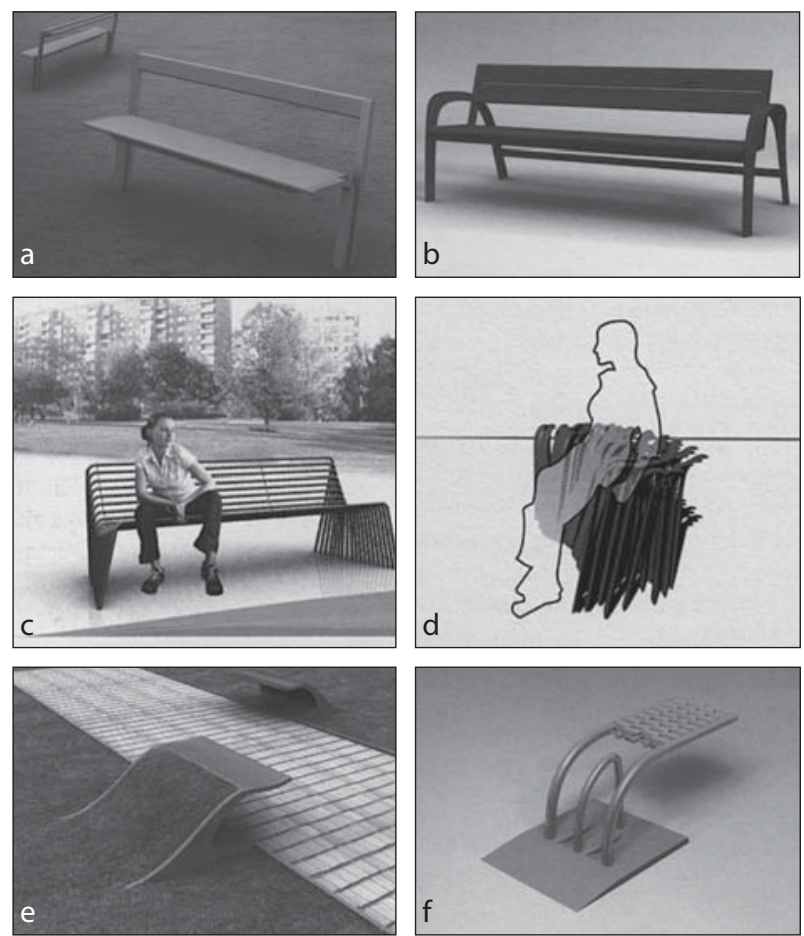

Figure 5: Park bench for Warsaw; M. Dąbrowski, 1. price (a), distinguish awards: M. Sobczak (b), M. Golędzinowska (c), J. Iwanicki (d), K. Włoch (e), S. Łobos (f). (Source: Broniatowska, 2006: 14) and well-considered landscape interior. All of its elements can not be selected without the place's context and its function. The important thing is, to consider and design them as a harmonized and complete whole. It applies to public spaces in particular, because their character requires precise
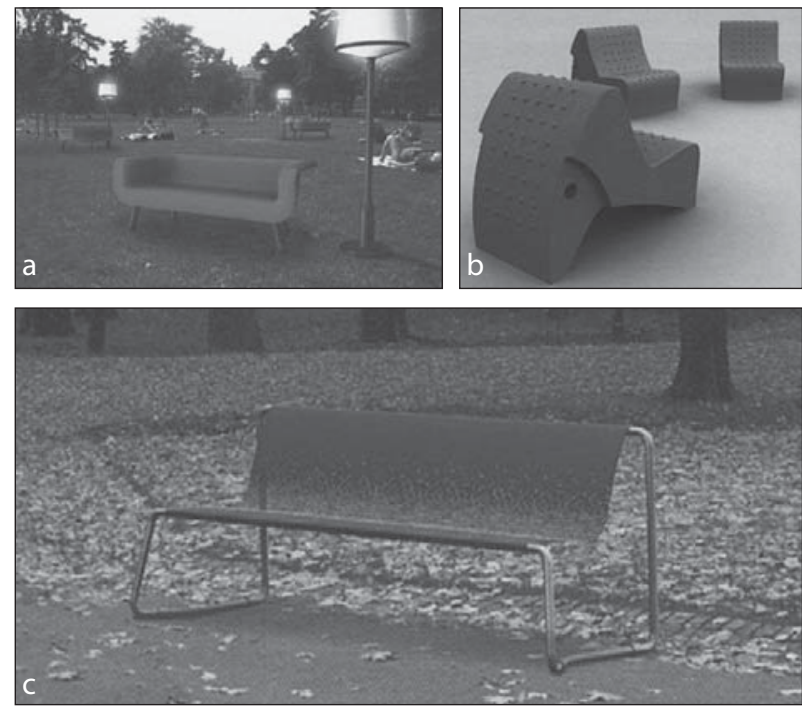

Figure 6: Park bench for Warsaw - distinguish awards: P. Stolarski (a), R. Szczepańska (b), K. Jankiewicz (c) (source: Broniatowska, 2006: 14) 
and complex designing process. Unfortunately, it seems that very few decision-makers in Polish cities are aware of it. The capital's authorities may be an exception, for their initiative in changing the street's signboards and houses' numbers in Warsaw, which is visited everyday by lots of lost tourists. Another action, showing a high awareness of authorities, was a student competition for park bench, organized by Head-architect of Warsaw (February 2006). The aim was to find a design, which would distinguish the city, make it nicer and much more representative. Looking at students' works, showed below, a furniture element in a public space can have a classic shape (Figure 5).

The students' proposals included also more innovative forms, though they excellently complied with landscape of a certain space (Figure 5).

This sort of details may also contrast with the surroundings, either by the colour of designed element, its' form or by used material (Figure 6).

Such contests, show the increasing need for taking care of city's image, even in detailed scale. These small elements, apart from for their utilitarian function, play significant role in ordering of the spatial composition, and so the aesthetic issue is also important.

The tendency of prefabricate technology, visible in building industry, caused that buildings along with details, are in majority deprived of individual, regional features, connected with tradition and lifestyle of citizens living in that part of a town (Wejchert, 1984).

Very often, these elements (neither the style nor material), do not refer in any way to existing architectural objects. So, instead of harmonizing, completing the interior, they are rather sort of dissonance. The strong need of being different and diverse is conducive to appearing of new forms. However, their unstoppable changing process makes the details impossible to function as signs, making the orientation in the area easier. In fact, they could actually cause disorientation. However, introducing exactly the same streetlamps, bus-stops or fences in spaces of different functions and character, is also not a good solution. The optimal solution is providing an aesthetic appearance and an appropriate vivid character selected especially for the type of an object (Figure 7, left). The example of rubbish presented, illustrates inconsistency of selection rules (Figure 7, right).

The furnishing elements of public spaces ought to divide and distinguish it to make it clear and coherent for a recipient. Among basic elements of streets' and urban squares' equipment, there are advertising elements. These are advertising signboards, bill-posts, billboards or also grand format advertising constructions.

The next group are elements of town's visual information, such as street signs, boards, signboards (streets' names), numbers, city clocks, bill-posts; quite important are also elements connected with keeping cleanness in city, such as: rubbish-bins, mobile toilets; For tourists the most important elements are those, which enable an easy access to various places like public communication stops, taxi stops and parking meters (Maass et al., 1979); From the aesthetic and utilitarian point of view, important are also elements used for lighting of urban spaces. And the others: benches, seats, shelters, roofing, play-ground equipment, flower beds and flower bowls. These are elements connected mostly with service and furniture of green spaces of the city. The last group includes interpersonal communication elements, such as: telephone booths, letter boxes etc.
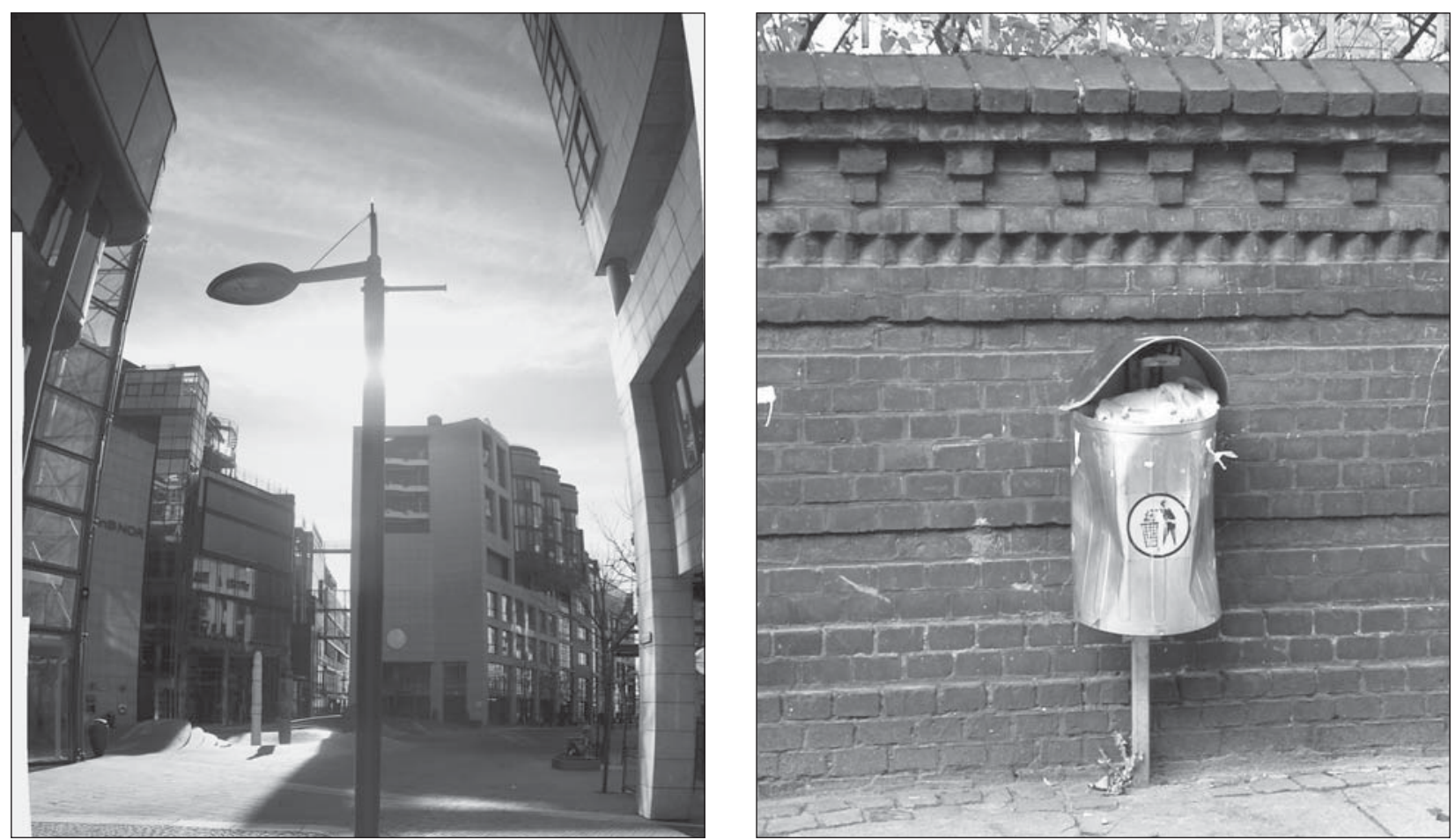

Figure 7: Streetlamp - Oslo (left) and rubbish-bin - Poznań (right) (source: Michalak et al., 2003). 

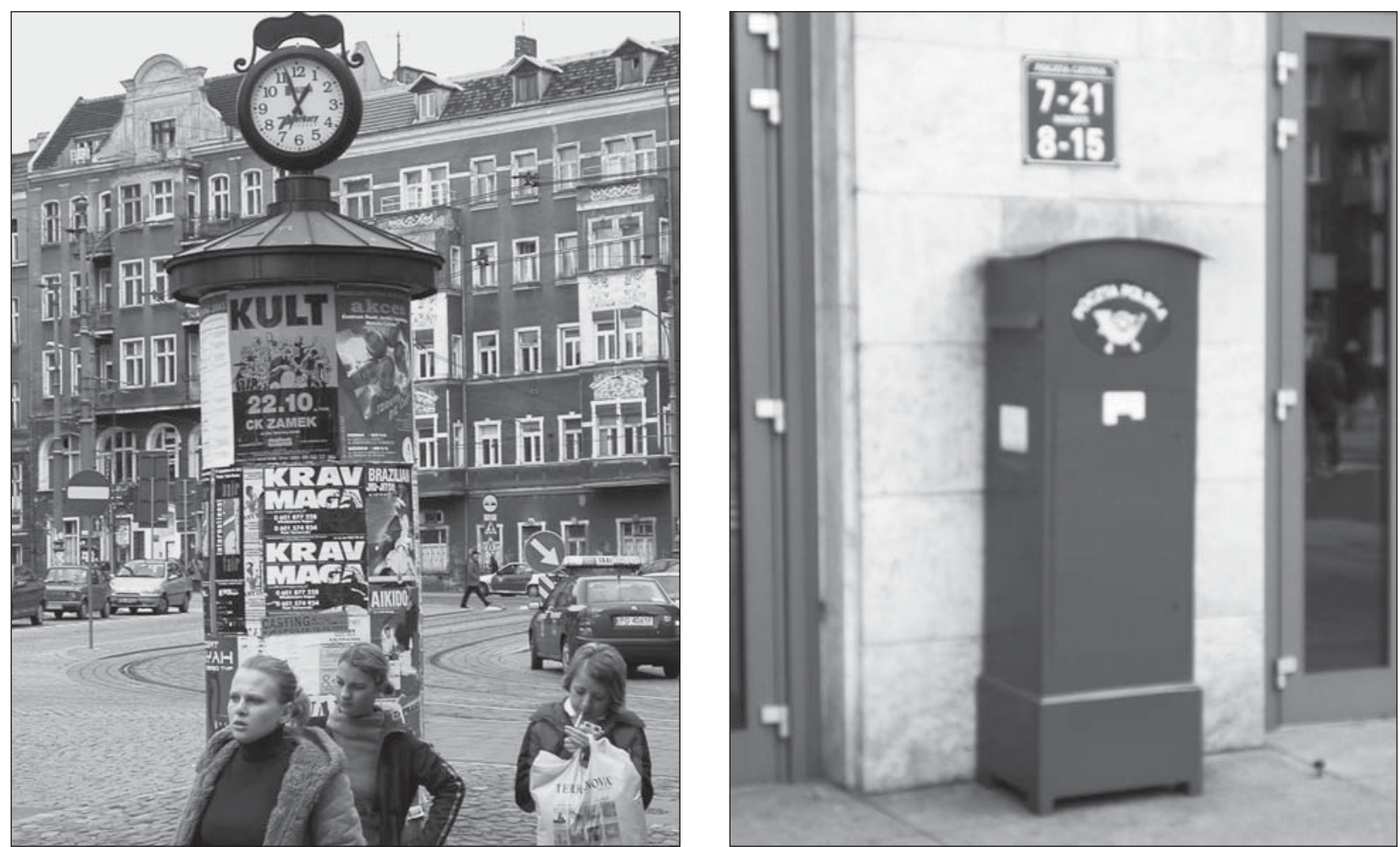

Figure 8: Bill-post with a clock (left) and letter box - Poznań (right) (source: Michalak et al., 2003).

Such elements as streetlamps, benches, rubbish bins, telephone booths, bill-posts, flower beds or fences; create a base of equipment of most of the built-up areas, that is why they have to come up to many different expectations. Introducing them into the space one should remember they are to harmonize not only with a certain interior but between one another as well. Therefore, it is recommended that for each interior those elements should be designed in groups, so called: families of details. Then, in one interior, all benches, streetlamps etc. could be created in the same style, form, assuring in this way fully harmonized spatial composition.
Apart from aesthetic values, important are also utilitarian features. Because of localization in public space, the main issue is their destruction resistance, caused by improper usage or just mere acts of vandalism. Another cause of destruction it is the influence of atmospheric factors, which is why a proper, systematic conservation should be provided. The additional advantage is the choice of an appropriate material, which not only guarantees a stable construction, but also atmospheric factors' resistance (Bartosiewicz, 1977). The aforementioned issues are very important, because the quality of the furnishings elements have a direct
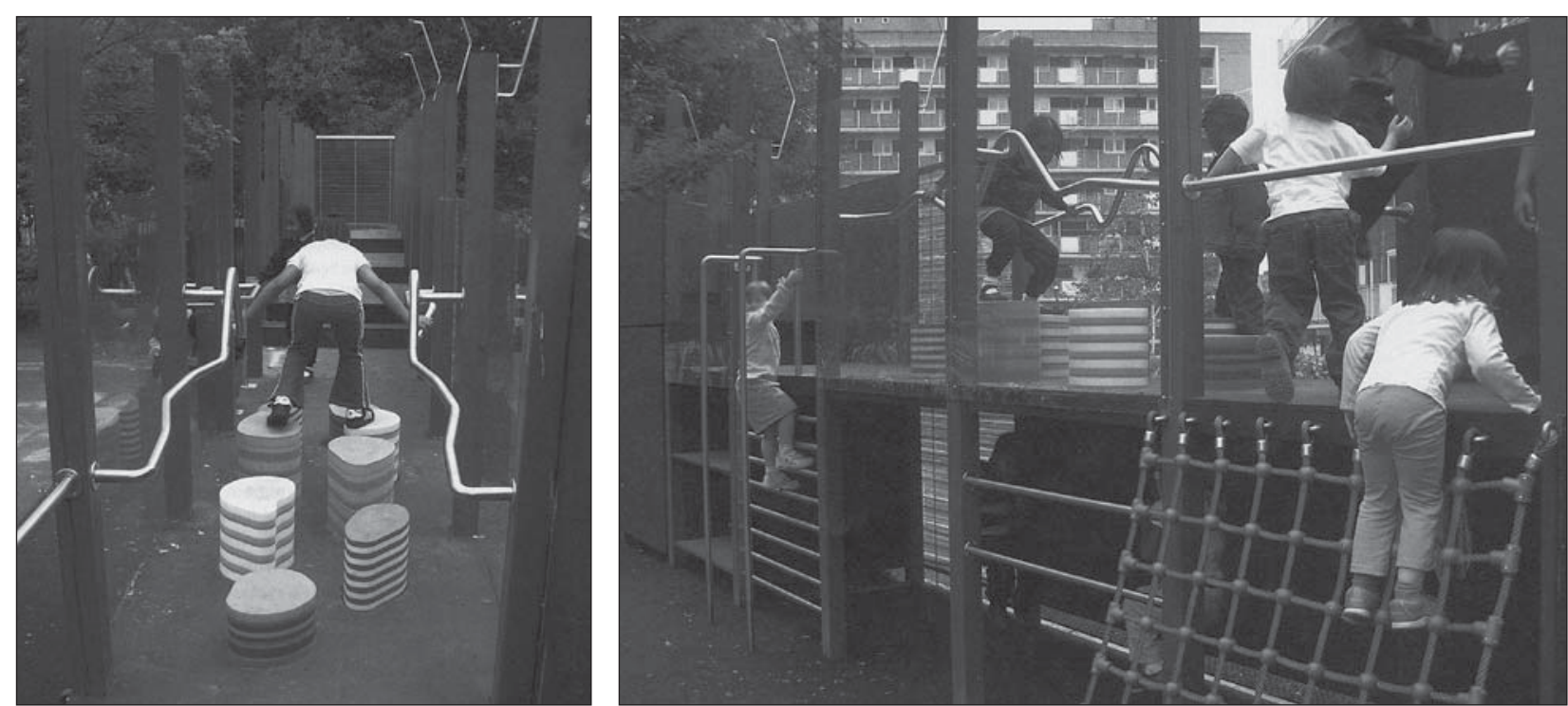

Figure 9: Play-ground by the St. Mary Nursery, Kilburn, London, designed by Sarah Wigglesworth Architects 2004 (source: Fiszer, 2006: 58) 

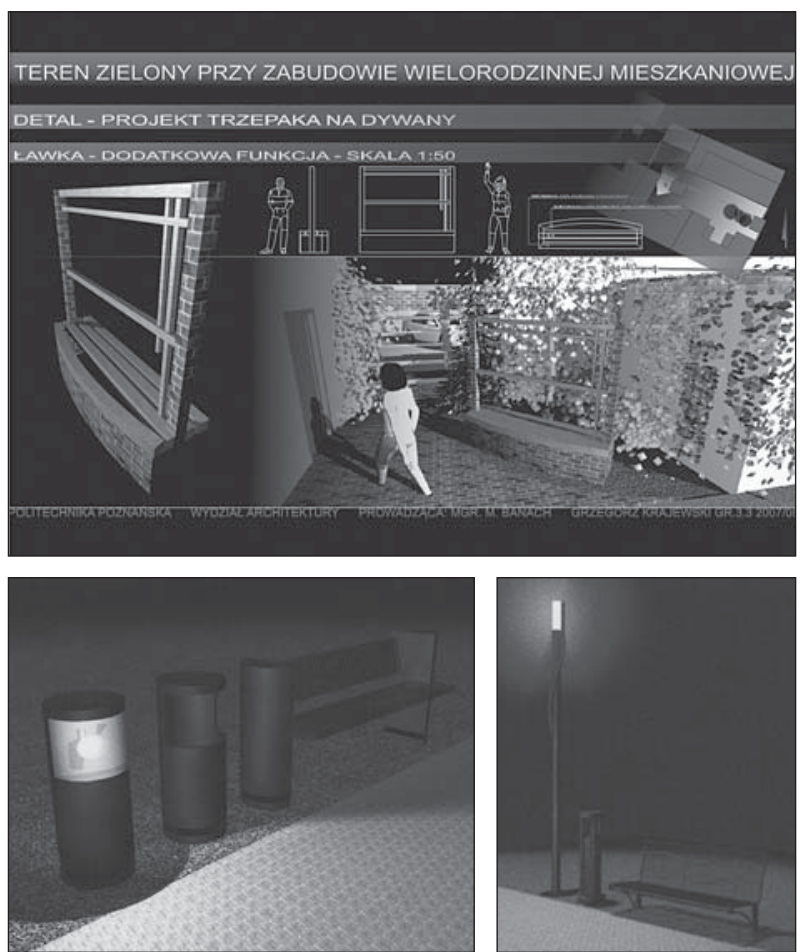

Figure 10: Carpet beating stand as a furnishing, Poznań, (G. Krajewski) and Family of details - Sołacki Park Poznań, Poland (M. Krzewina) (source: PUT Archive).
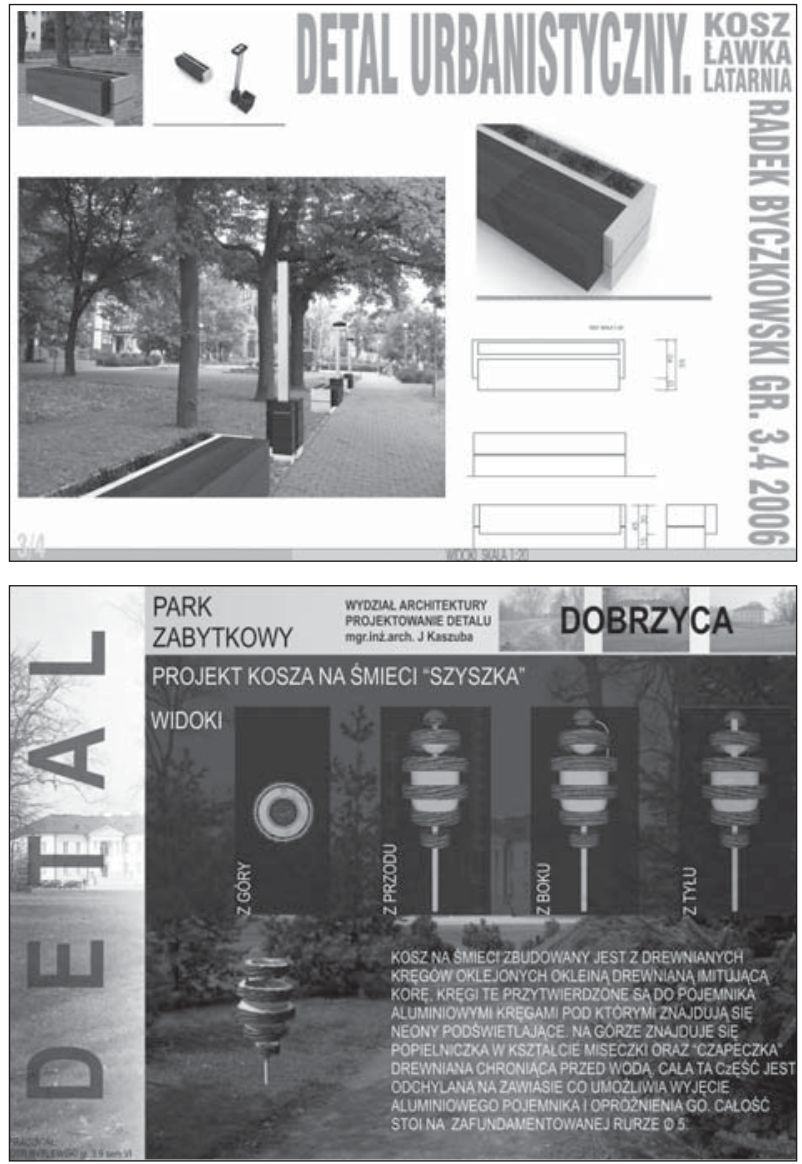

Figure 11: Details for City Park - Poznań (above) by R. Byczkowski and Historical Park -Dobrzyca (below) by P. Rytlewski, Poland (source: PUT Archive). influence on the quality of the space itself and the degree of usage comfort. Each and every element, depending on its type, is subject to the certain requirement. A bench ought to be comfortable and safe, rubbish-bin ought to be voluminous and easy to empty, and a street-lamp should ensure a good visibility both to the pedestrians and the motorized (Bartosiewicz, 1977).

There is also a special group of details, which fill such public spaces as play-grounds. Among other features, they must have a stable construction, lack of sharp edges etc. Above all, they have to be safe for young users, additionally they ought to be educational and encourage to play, just like the one in London (Figure 9).

The issue connected with influence of these small elements on a quality of reception and usage of public spaces, has been undertaken by students of Faculty of Architecture, at Poznan University of Technology. It has been a reaction to the problem of space and changing social behaviour patterns. Presented designs were prepared along with consideration of aesthetics, ergonomics, economy, ease of use, durability and visibility. For various public spaces, of different functions and characters, there have been proposed groups and single elements of equipment. First example, it is a detail for a small green square, which is also may be an ornament of the interior (Figure 10).

Completely different style of detail but innovative in character is an example of details designed for a square in Wilda (part of the city) area. The applied material that is wood and concrete constitutes a mix of stable construction and comfortable and interesting form (Figure 11).

Another examples are rather innovative, but used material (wood and concrete) gives a stable construction and a comfortable form (Figure 11, above) and next to it an unusual form of street-lamp for a historical park (Figure 11, below).

\section{Conclusion}

A modern city should be characterized with care for good orientation in the area, order and aesthetic side of its interiors. However, along with those aspects, another one must not be forgotten, which is the security. It depends on shape and relation between particular elements of the space whether good conditions for functioning of the city can be assured or whether in contrary multiplying pathological and aggression acts etc will aggravate. An appropriate organization and furnishings of this kind of space will surely help in giving comfort and security to its users (Czarnecki et al., 2004). Therefore these small elements should not be ignored in creating urban public spaces. The realization of these assumptions ought to be strengthened by conscious work of architect-urban planner (Broniatowska, 2006), who should take into account also a fact, that final aesthetic values of urban details like form, colour, proportion, material are determined by elements of dominating architectural objects and their function in a certain landscape. This creator should be able to predict the influence of introduced 
elements on an observer and user of the space at the same time (Wejchert, 1984). Such actions, ensure creation of unforgettable image of the city, readable and aesthetic, catching up with the times, but carrying also the features of local character.

Marzena Banach-Ziaja, Architect

Poznan University of Technology, Faculty of Architecture, Poznan

E-mail: marzena.banach@erba.com.pl

\section{References}

Bartosiewicz, A. (1977) Furnishings of The Green Spaces. Warszawa, WSiP. Broniatowska, M. (2006) Park Bench Competition. Architecture \& Business, 5, pp.14.

Cerver, F. (1996) Landscape Architecture. The Word of Environmental Design. Barcelona, Arco Editorial.

Czarnecki, B., and Siemiński W. (2004) Shaping of a Safe Public Space. Warszawa, Bialystok University of Technology, Consulting and Information Centre Difin Itd.

Fiszer T. (2006) World Acquainting Machine. Architecture \& Business, 10, pp. 58-59.
Frampton K., Futagawa Y. (2000) Modern Architecture 1851-1945. New York, Rizzoli.

Internet 1: http://fotogalerie.pl/fotka/2741891174861772843,ruranski,T rafalgar-Square-londyn.htm;jsessionid=19DE4A04E7BB21E8C4C5915E 5961DE72 (Date accessed, 28. 10. 2008).

Internet 2: http://www.swiatpodrozy.pl/i.php?g=212\&n=26 (Date accessed, 28. 10. 2008).

Maass J., and Referowska M. (1979) The Equipment of Cities' Public Spaces. Warszawa, Łódż, PWN

Michalak, H. (2000) Detail as an Element of Personification of Architecture. Gliwice, Silesian University.

Michalak, H., Banach-Ziaja, M., and Kobryński, P. (2003) Urban Detail in Spatial Planning. Poznań, Poznan University of Technology.

Wejchert, K. (1984) Elements of Urban Composition. Warszawa, Arkady. Wejchert, K. (1993) The Space Around Us. Katowice, Fibak Norma Press.

Picture Book of Britain in Colour (1971). London, The Humlyn Publishing Group Ltd.

Spatial Planning and Developing Law. Official Register of Acts of Poland No. 80/717. Warszawa.

Private Archive of the author - photos of USA (2007).

PUT Archive - Poznan University of Technology Archive of Students' Works (2006/2007). III-rd year of study at the Faculty of Architecture. 